\title{
Update on anaesthesia and the immune response
}

\begin{abstract}
Infection following surgery is common. Although many factors have been implicated in the pathogenesis of perioperative infection, ultimately depression of the host defence mechanisms allows the invading organisms to become established. Therefore, an understanding of anaesthesia-induced immunosuppression or stimulation is essential in order to combat morbidity and mortality from perioperative infection, tumour growth and metastasis, and drug mediated hypersensitivity. The objective of this refresher course is to review briefly the different components of the immune response and to present pertinent evidence relevant to anaesthesia-induced suppression and/or stimulation of the immune response. The clinical significance of these effects of anaesthesia on the immune response will be explored.
\end{abstract}

\section{The immune response}

The ability of the body to recognize, resist, and remember foreign cells and organisms as "non self" forms the basis of the immune response. ${ }^{1}$ This ability to protect against "non self" or foreign molecules involves both "non specific" and "specific" components of the immune response.

\section{Non specific immunity \\ The "non-specific" or "innate" immunity is geneti- cally determined and does not require previous exposure to the invading organisms or antigens. It forms the first line of defence, consisting of a humoral and a cellular component. Upon stimula- tion there is complement activation, increased capillary permeability, attraction of polymorphs, monocytes and macrophages, and enhanced phago- cytic and intracellular bactericidal activities. The net result is the establishment of a typical inflam- matory reaction.}

Specific immunity

"Specific" or "acquired" immunity is an adaptive response that requires previous exposure to a foreign substance. In all vertebrates, the smal lymphocyte is the basic unit of the immune response since it specifically recognizes the foreign antigen. The information concerning the antigen is presented to the lymphocyte, probably in the form of RNA, following phagocytosis, digestion and processing of the antigen by macrophages. The immunocompetent lymphocytes are classified on an anatomical and functional basis into either thymus dependent or $T$ lymphocytes, or bursa dependent $B$ lymphocytes $^{2}$ (Bursa of Fabricius of the chicken).

\section{T LYMPHOCYTES}

T lymphocytes are so called because they mature in the thymus and are responsible for cell-mediated immunity. On stimulation by appropriate antigens, $\mathrm{T}$ cells transform into lymphoblasts, produce soluble mediators called lymphokines and generate cytotoxic cells. The $\mathrm{T}$ cells are further subdivided into three groups according to their functional activities.

\section{T HELPER OR T4 LYMPHOCYTE}

Following interaction with macrophages and antigens, these cells help B cells transform into plasma cells and manufacture more antibody. They also release lymphokines and these cells mount the delayed hypersensitivity response.

\section{T SUPPRESSOR OR T8 LYMPHOCYTE}

These cells fine tune the immune response by having an inhibitory effect on the B cell antibody synthesis. T-suppressor cells also exercise an inhibitory control over cytotoxic or effector $\mathrm{T}$ cells and the macrophages.

Department of Anaesthesia, McMaster University Medical Centre, 1200 Main Street West, Hamilton, Ontario L8N 3ZS 


\section{T EFFECTOR LYMPHOCYTES}

These cells possess specific cytotoxic capabilities and can lyse foreign cells, including tumour cells, by direct contact.

In addition to $\mathrm{T}$ and $\mathrm{B}$ lymphocytes, other subclasses of lymphocytes include the following:

\section{K OR KILLER CELLS}

These lymphocytes do not bear either $\mathrm{T}$ or $\mathrm{B}$ cell surface markers but have an affinity for, and will lyse, target cells coated with a specific immunoglobulin.

\section{NK OR NATURAL KILLER CELLS}

This group of null cells without surface markers possess the ability to kill malignant cells directly without antibody coating or complement activation. These cells are probably regulated by suppressor cells and they do not attack the normal cells.

\section{B LYMPHOCYTES}

B cells are concerned with the synthesis of circulating antibodies and are fundamental to the humoral immune response. Following antigenic stimulation, the B cells are transformed to plasma cells capable of producing various types of immunoglobulin against the circulating antigens. These circulating antibodies confer humoral immunity that can be passively transferred from one individual to another. The synthesis and release of free antibody by the plasma cells results in coating of the antigenic pathogens with a specific antibody and complement which leads to the lysis of the pathogenic organism. Although the T and the B lymphocytes specifically participate in either the cellular or the humoral components of the immune response, their activities are always interrelated with each other and other cell types which allows amplification and regulation of the various aspects of the host defence system.

\section{Anaesthesia and the immune response}

The possibility that anaesthesia may alter the immune function was considered as early as 1903 when Snel reported that ether, chloroform, and chloral hydrate increased the mortality from anthrax in guinea pigs. ${ }^{3}$ In recent years, several extensive reviews have revealed that anaesthesia can adversly affect both non-specific and specific components of the immune response. ${ }^{4-8}$
Anaesthesia and leucocyte chemotactic migration The migration of polymorphs, monocytes and other phagocytic cells is one of the earliest events in the body's defence against infection. Therefore, effects of anaesthetic agents on the leucocyte migration were investigated by several workers. Initial studies by Moudgil et al. ${ }^{9}$ using modified Boyden's chambers (where migration across a micropore filter was measured), revealed a dose-dependant depression of chemotactic migration by local, intravenous and inhalational anaesthetic agents. This depression occurred at the clinical concentrations of all the agents, was short-lived and reversible. A similar inhibition of leucocyte locomotion by intravenous anaesthetic agents was also observed in vitro by others more recenntly. ${ }^{10}$ Similar findings were also reported by Stanley ${ }^{11}$ and confirmed by Moudgil ${ }^{12}$ in patients having surgery under general anaesthesia.

In contrast, in vitro studies by Duncan and Cullen ${ }^{13}$ and Nunn et al. ${ }^{14}$ failed to reveal any depression of leucocyte migration by thiopentone or halothane. In order to clarify these contradictory findings Moudgil et al. ${ }^{15}$ conducted studies of the effects of equipotent concentrations of different volatile anaesthetic agents and 70 per cent nitrous oxide on the polymorph and monocyte chemotactic migration. These studies showed that the neutrophil migration following exposure to one $\mathrm{MAC}$ concentrations of isoflurane, enflurane, halothane, methoxyflurane and 70 per cent nitrous oxide was reduced to $92,68,50,42$ and 45 per cent of the control activity respectively. Similarly, monocyte migration was reduced to $95,76,68,61$ and 49 per cent of the control activity with the respective agent.

The concensus at present is that all anaesthetic agents cause a short-term, reversible depression of chemotactic migration. The mechanisms whereby anaesthetic agents induce an inhibition of chemotaxis remain to be defined. This depression of chemotactic migration could be clinically relevant in relation to perioperative infection.

\section{Anaesthesia and phagocytosis}

An intact phagocytic function is essential for the host defence. Several human and animal studies of anaesthetic effects of phagocytic activity in the past have produced contradictory evidence. At the turn of the century animal studies concluded that ether 
and chloroform ${ }^{17}$ inhibited phagocytosis in a dose dependent manner. Similarly a reduction in the number of salmonella bacteria ingested by peritoneal neutrophils after halothane anaesthesia in mice has also been reported. ${ }^{18}$

Human studies after either halothane, or nitrous oxide-narcotic anaesthesia without surgery, revealed a decrease in phagocytosis of latex particles and nitroblue tetrazolium (NBT) reduction in one instance, but showed only a minimal inhibition in another after halothane $0.5-2.5$ per cent or nitrous oxide 80 per cent. ${ }^{19}$ Reduced phagocytic activity by fixed macrophages of the reticuloendothelial system has also been reported during anaesthesia in man, ${ }^{20}$ and in animals, ${ }^{21}$ although the reduction was only minimal. In addition to the effects of volatile inhalational anaesthetic agents, in a recent study the effects of premedicants, intravenous induction and local anaesthetic agents, on the human leucocyte phagocytic activity were assessed in vitro. This study revealed a dose dependant, statistically significant depression of phagocytic activity following in vitro exposure to varying concentrations of intravenous induction agents, narcotics, and local anaesthetic agents. These observations were not the result of a non-specific drug concentration effect, since equimolar concentrations of other non-anaesthetic agents failed to produce any depression of phagocytosis. ${ }^{22}$

Thus it would appear that some of the anaesthetic agents may potentially enhance the risk of perioperative infection by reducing the phagocytic activity. This depression may be further compounded by the surgical intervention per se, since several other studies have shown impaired leucocyte function by the stress of surgery both in man and in animals.

\section{Anaesthesia and bactericical activity}

In addition to a decrease in phagocytosis, anaesthetic agents can also inhibit bactericidal activities. Earlier studies utilized nitroblue tetrazolium reduction (NBT reduction) as an index of cidal activity. More recently, utilizing the technique of chemiluminescence, where the light emission by the highly reactive and excited oxygen radical is evaluated, it was shown that only enflurane and not isoflurane inhibited the bactericidal activity. ${ }^{23}$ Similar observations were made following exposure to halothane also. ${ }^{24}$ Using the superoxide induced chemiluminescence, a dose-dependant depression of bactericidal activity was also reported with thiopentone and althesin; however, methohexitone, morphine, diazepam and lidocaine failed to produce similar effects. ${ }^{25}$

All the above studies support the concept that different anaesthetic agents may interfere with various aspects of the non-specific immune response. A suppression of leucocyte function in particular could be relevant in the pathogenesis of postoperative infection. However, the true clinical significance of these observations remains to be ascertained.

\section{Anaesthesia and lymphocyte function}

The ability of the peripheral blood lymphocytes to proliferate in response to mitogenic (PHA) or alloantigenic stimulation is a recognized in vitro correlate of cell-mediated immunity. Similarly lymphocyte cytotoxicity, and T helper (T4) and T suppressor (T8) cell ratios are also utilized to assess the lymphocyte immunocompetence in cell-mediated immunity.

Several studies have investigated the effects of inhalational, intravenous and local anaesthetic agents on the lymphocytes' ability to proliferate following mitogenic stimulation with phytohaemagglutinin (PHA) in tissue cultures in vitro. Halothane was found to decrease PHA-induced lymphocytic proliferation in vitro in concentrations found during clinical anaesthesia but only after 24 to 48 hours' exposure to halothane. ${ }^{26}$ Similarly cell-mediated cytotoxicity, an important defence against malignant cells, was also inhibited by exposure to 1.0 to 2.5 per cent halothane in vitro. ${ }^{27}$

In another study thiopentone was seen to inhibit cytotoxicity reaction at the peak concentrations found during the induction of anaesthesia and also decrease PHA induced lymphoproliferation at higher concentrations of the agent. ${ }^{28}$ Ketamine, droperidol, or lidocaine did not affect lymphocyte transformation at clinical concentrations, but were able to cause a depression at much higher concentrations. ${ }^{29}$ Addition of several anaesthetic agents to the lymphocyte cultures simultaneously produced additive effects. One per cent halothane and thiopentone $\left(14 \mu \mathrm{g} \cdot \mathrm{ml}^{-1}\right)$ inhibited cytotoxicity reaction by $20-21$ per cent separately but when added simultaneously to the cultures caused a 45 per cent inhibition. ${ }^{30}$ Thus, it is clear that anaesthetic agents 
cause a depression of mitogenic lymphoproliferation as well as cell-mediated cytotoxicity in vitro.

However, the studies of the effect of clinical anaesthesia on lymphocyte function in man have yielded differing opinions. Halothane and enflurane anaesthesia for 5-7 hours duration in healthy volunteers had no effect on the phytohaemagglutinin-induced lymphoproliferation in one study. However, a decrease in mitogen (PHA) and alloantigen (MLC) induced lymphoproliferation was observed after three hours exposure to halothane/ $\mathrm{N}_{2} \mathrm{O} / \mathrm{O}_{2}$ anaesthesia in healthy humans, in another similar study. ${ }^{32}$ The intensity of depression of lymphocyte function was more severe when a similar halothane $/ \mathrm{N}_{2} \mathrm{O} / \mathrm{O}_{2}$ anaesthesia was repeated six weeks after phenobarbitone pretreatment. In contrast to the depression observed with halothane/ $\mathrm{N}_{2} \mathrm{O} / \mathrm{O}_{2}$ anaesthesia, balanced anaesthesia with thiopentone $/ \mathrm{N}_{2} \mathrm{O} / \mathrm{O}_{2}$ fentanyl droperidol/muscle relaxant, failed to produce a depression of PHA induced lymphocyte responses. ${ }^{33,34}$ In a recent unpublished study by Moudgil and Singal it was observed that halothane but not isoflurane inhibited PHA-induced lymphoproliferation in the postoperative period.

The effects of regional versus general anaesthesia on the immune response have also been investigated recently. A significant reduction of lymphoproliferation in response to mitogens and histo-compatibility alloantigens in mixed lymphocyte cultures was observed in patients having transurethral prostatic resection under general anaesthesia, ${ }^{35}$ whereas only minimal changes were seen when surgery was performed under spinal anaesthesia. Similarly, natural killer (NK) cell activity was significantly depressed in mothers having Caesarean section under general anaesthesia only and not under epidural anaesthesia. ${ }^{36}$

A depression of monocyte mediated cytolysis and mitogen induced lymphoproliferation by sera obtained from patients having general anaesthesia but not epidurals has also been reported. ${ }^{37}$ These and other studies would indicate that as opposed to general anaesthesia, surgery under regional anaesthesia does not produce a suppression of cellmediated immunity.

Anaesthesia and humoral antibody production Reports on the effects of anaesthesia on humoral immunity in man are meagre with inconclusive results. Although a slight decrease of immunoglobulin concentrations in the postoperative period has been reported, ${ }^{38}$ there is no firm evidence that anaesthesia alters the production, functional activity or immunoglobulin levels in the perioperative period. The postoperative slight decrease of immunoglobulin levels is predominantly due to protein loss from the intravascular space and not anaesthesia per se. Since the half-life of serum immunoglobulins is long, i.e., 2.4 ( $\operatorname{lgE}$ ) to 21 days (IgG), transitory disturbances in immunoglobulin production are unlikely to be reflected in serum concentrations. However, a decrease of immunoglobulin plaque-forming cells has been reported following open heart surgery. ${ }^{39,40}$ On the basis of animal experiments and measurements made after battle injuries, it would appear that antibody production remains unaltered after surgery and anaesthesia.

\section{Anaesthesia and infection}

It is difficult to ascertain the precise role of anaesthesia in the pathogenesis of perioperative infection since several factors contribute towards it. However, several animal studies have shown that anaesthetic intervention alone may alter the course of an infection. Halothane anaesthesia has been shown to increase the mortality from salmonella infection in mice ${ }^{18}$ in one study and double the mortality from faecal peritonitis in another. ${ }^{42} \mathrm{Halo}$ thane anaesthesia for two hours was also reported to have increased mortality from murine hepatitis virus $\left(\mathrm{MHV}_{3}\right)$ infection in newly weaned mice. ${ }^{41}$ The mortality in the anaesthetized group of animals was significantly enhanced when anaesthesia was given immediately before and up to 24 hours after infection. ${ }^{42}$ These and other animal studies tend to support the view that anaesthesia can enhance morbitity and mortality from infection by modifying the host defences.

\section{Anaesthesia and malignancy}

In studies of cell-mediated immunity against tumour cells in man, presence of tumour-associated antigens has been confirmed by several laboratories. It appears that neoplastic cell is antigenic and that cell mediated immune responses of the host tend to inhibit tumour growth. Studies of effects of anaesthesia on "tumour takes" are contradictory. Both enhanced pulmonary metastasis ${ }^{43}$ as well as 
no significant effect by anaesthesia, ${ }^{44}$ have been reported. Besides general tests of overall immunity, tumour-specific responses have also been evaluated in the perioperative period. The ability of the host leucocytes to kill tumour cells (tumour type specific leucocytotoxicity) was depressed up to seven days following mastectomy under halothane anaesthesia for carcinoma of the breast ${ }^{45}$ and Wilms tumour. ${ }^{46}$ Tumour cell killing by cytotoxic leucocytes was also inhibited by local anaesthetics, ${ }^{47}$ barbital ${ }^{48}$ and halothane in vitro. ${ }^{27}$ Although it is difficult to assess the anaesthetic effects in isolation from surgical intervention, from the above studies it would appear that anaesthesia and surgery may enhance tumour spread by suppressing the immune responses.

\section{Anaesthesia and anaphylaxis}

Anaphylactic drug reactions are the outcome of an undue and unwanted stimulation of the immune response. True anaphylactic hypersensitivity requires previous sensitization and in all the subtypes (Type I to Type IV) allergic reactions are mediated through antibodies or cell-mediated immune responses. Although anaesthetic agents cause a depression of the immune response, they do not provide any protection against anaphylactic drug reactions.

\section{Conclusions}

The available evidence supports the concept that anaesthetic agents influence a wide variety of specific and non-specific host defences. However, the precise role of anaesthesia alone in the pathogenesis of perioperative infection remains to be defined. Although large amounts of data demonstrate postoperative impairment of the immune response, further studies are necessary to correlate in vivo and in vitro studies of immunocompetence and the occurrence of postoperative infections. Anaesthetic-induced depression of immune system is short-lived and reversible; however, this depression can influence perioperative morbidity and mortality in the susceptible patients. By understanding the nature of these defects, and by meticulous preoperative and intraoperative management, we may be able to prevent the perioperative morbidity and mortality.

\section{References}

1 Roitt I. Essential Immunology. 4th Ed. Blackwell Scientific Publications 1980.

2 McIrvine AJ, Mannick JA. Lymphocyte function in the critically ill surgical patient. Surg Clin North Am 1983; 63: 245-61.

3 Snel JJ. Immunitat und Norkose. Berlin Klin Wochenschr 1903; 40: 212.

4 Moudgil GC, Wade AG. Anaesthesia and immunocompetence. Br J Anaesth 1976; 48: 31-9.

5 Duncan $P G$, Cullen $B F$. Anesthesia and immunology. Anesthesiology 1976; 45: 522-38.

6 Walton $B$. Anaesthesia, surgery and immunology. Anaesthesia 1978; 33: 322-48.

7 Kehlet $H$, Wandall JH, Hjortso NC. Influence of anesthesia and surgery on immunocompetence. Regional Anesthesia 1982; 7: S68-S74.

8 Ryhanen $P$. Effects of anesthesia and operative surgery on the immune response of patients of different ages (thesis). Oulu, Finland: Oulu University, 1977.

9 Moudgil GC, Allan RB, Russell RJ, Wilkinson PC. Inhibition, by anaesthetic agents, of human leucocyte locomotion towards chemical attractants. $\mathrm{Br} \mathrm{J}$ Anaesth 1977; 49: 97-105.

10 Mathiue A, Mathiue D, Hyslop N. Effect of induction agents and non-volatile anesthetics on chemotaxis of polymorphonuclear leucocytes. Anesthesiology 1979; 51: S56.

11 Stanley TH, Hill GE, Portas MR, Hogan NA, Hill $H R$. Neutrophil chemotaxis during and after general anesthesia and operation. Anesth Analg 1976; 55: 668-73.

12 Moudgil GC, Pandya AR, Ludlow DJ. Influence of anaesthesia and surgery on neutrophil chemotaxis. Can Anaesth Soc J 1981; 28: 232-8.

13 Duncan $P G$, Cullen $B F$. Neutrophil chemotaxis and anaesthesia. Br J Anaesth 1977; 49: 345-9.

14 Nunn JF, Sturrock JE, Jones AJ et al. Halothane does not inhibit human neutrophil function in vitro. Br J Anaesth 1979; 51: 1101-8.

15 Moudgil GC, Gordon J, Forrest JB. Comparative effects of volatile anaesthetic agents and nitrous oxide on human leucocyte chemotaxis in vitro. Can Anaesth Soc I 1984; 31: 631-7.

16 Graham EA. The influence of ether and ether anaesthesia on bacteriolysis, agglutination and phagocytosis. J Infect Dis 1911; 8: 147-75.

17 Hamburger $H J$. Researches on phagocytosis. $\mathrm{Br}$ Med J 1916; 1: 37. 
18 Bruce DL. Effect of halothane anesthesia on experimental salmonella peritonitis in mice. J Surg Res 1967; 7: 180-5.

19 Cullen, $B F$. The effect of halothane and nitrous oxide on phagocytosis and human leukocyte metabolism. Anesth Analg 1974; 53: 531-6.

20 Lofstrom $B$, Schildt $B$. Reticuloendothelial function under general anesthesia. Acta Anaesthesiol Scand 1974; 18: 34-40.

21 Goldstein E, Munson ES, Eagle C et al. The effects of anesthetic agents on murine pulmonary bactericidal activity. Anesthesiology 1971; 34: 344-52.

22 Moudgil GC. Effect of premedicant, intravenous anaesthetic agents and local anaesthetics on phagocytosis in vitro. Can Anaesth Soc J 1981; 28: 597 602.

23 Welch WD, Zaccari J. Enflurane, but not isoflurane, inhibits neutrophils. Anesthesiology 1981; 55: A293.

24 Welch WD. Halothane reversibly inhibits human neutrophil bacterial killing. Anesthesiology 1981; 55: $650-4$

25 White IWC, Gelb AW, Wexler HR, Stiller CR, Keown $P A$. The effects of intravenous anaesthetic agents on human neutrophil chemiluminescence. Can Anaesth Soc J 1983; 30: 506-11.

26 Bruce $D L$. Halothane action on lymphocytes does not involve cyclic AMP. Anesthesiology 1976; 44: 151-4.

27 Cullen BF, Duncan PG, Ray-Keil L.. Inhibition of cell-mediated cytotoxicity by halothane and nitrous oxide. Anesthesiology 1976; 44: 386-90.

28 Park SK, Brody JI, Wallace HA, Blakemore WS. Immunosuppressive effect of surgery. Lancet 1971; 1: 53-5.

29 Watkins J, Matti S. In: Trauma, Stress and Immunity in Anaesthesia and Surgery. Butterworth \& Co. Ltd. 1982.

30 Duncan PG, Cullen BF, Ray-Keil L. Thiopental inhibition of tumour immunity. Anesthesiology 1977; 46: 97-101.

31 Duncan $P G$, Cullen BF, Calverly $R$ et al. Failure of enflurane and halothane anesthesia to inhibit lymphocyte transformation in volunteers. Anesthesiology 1976; 45: 661-5.

32 Doenicke A, Grote B, Suttmann $\mathrm{H}$ et al. Effects of halothane on the immunological system in healthy volunteers. Clinical Research Reviews 1981; 1 : 23-8.
33 Salo $M$. The effect of anaesthesia and total hip replacement on the phytohaemagglutinin and concanavalin A responses of lymphocytes. Annales Chirurgiae et Gynaecologiae 1977; 66: 299-303.

34 Salo $M$. Effect of anaesthesia and open-heart surgery on lymphocyte responses to phytohaemagglutinin and concanavalin A. Acta Anaesthesiol Scand 1978; 22: 471-4.

35 Whelan P, Morris PJ. Immunological responsiveness after transurethral resection of the prostate: general versus spinal anaesthetic. Clin Exp Immunol 1982; 48: 611-8.

36 Ryhanen $P$, Jouppila $R$, Lanning $M$ et al. Natural killer cell activity after elective Cesarean section under general and epidural anesthesia in healthy parturients and their newboms. Gynecol Obstet Invest 1985; 19: 139-42.

37 Hole A. Per- and postoperative monocyte and lymphocyte functions: effects of sera from patients operated under general or epidural anaesthesia. Acta Anaesthesiol Scand 1984; 28: 287-91.

38 Cohnen $G$. Changes in immunoglobulin levels after surgical trauma. J Trauma 1972; 12: 249-54.

39 Salo $M$, Eskola J, Viljanen $M K$, Ruuskanen $O$. B-lymphocyte activation during anaesthesia and open heart surgery. Abstract. Acta Anaesthesiol Scand 1981; 25: 67.

40 Eskola J, Salo $M$, Viljanen MK, Ruuskanen O. Impaired $B$ lymphocyte function during open-heart surgery: effects of anaesthesia and surgery. Br J Anaesth 1984; 56: 333-43.

41 Duncan PG, Cullen BF, Pearsall N. Anesthesia and the modification of the response to infection in mice. Anesth Analg 1976; 55: 776-81.

42 Moudgil GC. Influence of halothane on mortality from murine hepatitis virus $\left(\mathrm{MHV}_{3}\right) . \mathrm{Br} \mathrm{J}$ Anaesth 1973; 45: 1236.

43 Agostino D, Cliffton EE. Anesthetic effect on pulmonary metastases in rats. Arch Surg 1964; 88: $735-9$.

44 Schatten WE, Kramer WM. An experimental study of postoperative tumour metastases. II: Effect of anesthesia, operation and cortisone administration on growth of pulmonary metastases. Cancer 1958; 11: 460-2.

45 Vose BM, Moudgil GC. Effect of surgery on tumour-directed leucocyte responses. Br Med J 1975; 1: 56-8.

46 Kumar $J$, Taylor $G$. Effect of surgery on 
lymphocytotoxicity against tumor cells. Lancet 1974; 1: 1564-7.

$47 \mathrm{Kemp}$ AS, Berke G. Inhibition of lymphocyte mediated cytolysis by the local anesthetics benzyl and salicyl alcohol. Eur J Immunol 1973; 3: 674-7.

48 Lee SK, Singh J, Taylor RB. Subclasses of $\mathrm{T}$ cells with different sensitivities to cytotoxic antibody in the presence of anesthetics. Eur I Immunol 1975; 5: 259-62. 